\title{
Eprosartan-based hypertension therapy, systolic arterial blood pressure and cognitive function: analysis of Middle East data from the OSCAR study
}

\author{
This article was published in the following Dove Press journal: \\ Vascular Health and Risk Management \\ | August 201। \\ Number of times this article has been viewed
}

\author{
Ghazi Ahmad Radaideh' \\ Patrick Choueiry ${ }^{2}$ \\ Amr Ismail ${ }^{2}$ \\ Elie $\mathrm{Eid}^{3}$ \\ Jean-Pascal Berrou ${ }^{4}$ \\ Armand Sedefdjian ${ }^{5}$ \\ Frank Sévenier ${ }^{6}$ \\ Atul Pathak ${ }^{7}$ \\ 'Rashid Hospital of Dubai, Dubai, United \\ Arab Emirates; ${ }^{2}$ Abbott Gulf - Levant; \\ ${ }^{3}$ Division of Cardiology, American \\ University of Beirut, Beirut, Lebanon; \\ ${ }^{4}$ Abbott Products Operations AG, \\ Allschwill, Switzerland; ${ }^{5}$ EvidenceBased \\ Communication (EBC), Rueil- \\ Malmaison, France; ${ }^{6}$ Fovéa Group, Rueil- \\ Malmaison, France; ${ }^{7}$ Departments of \\ Clinical Pharmacology and Cardiology, \\ Institut National de la Santé et de la \\ Recherche Médicale UI048, Université \\ de Toulouse-UPS, Centre Hospitalier \\ Universitaire de Toulouse, Toulouse, \\ France
}

Correspondence: Ghazi Ahmad Radaideh Rashid Hospital of Dubai, PO Box 4545, Dubai, United Arab Emirates

Tel +97143374000

Fax+97|43368I52

Email garadaideh@dohms.gov.ae
Background: Studies have indicated a relationship between hypertension and cognitive function. The possible effect of antihypertensive therapy on cognitive disorders is therefore a matter of interest.

Materials and methods: The Observational Study on Cognitive function And SBP Reduction (OSCAR) was an open-label, multinational trial designed to evaluate the impact of eprosartanbased antihypertensive therapy on cognitive function in patients with essential hypertension. Eprosartan $600 \mathrm{mg} /$ day for 6 months (with provision for additional medication as needed) was initiated in hypertensive subjects aged $\geq 50$ years. A total of 853 patients in an intention-to-treat cohort from seven countries of the Middle East was identified for subgroup analysis.

Results: Arterial blood pressure was reduced significantly $(P<0.001)$ during the study: At the end of 6 months of eprosartan-based therapy, the mean $( \pm \mathrm{SD})$ reduction from baseline was $32.1 \pm 14.3 / 14.6 .3 \pm 8.6 \mathrm{mmHg}(P<0.001)$. Mean pulse pressure was reduced by $18.3 \pm 13.1 \mathrm{mmHg}(P<0.0001$ vs baseline). Blood pressure was normalized (systolic $<140 \mathrm{mmHg}$ and diastolic $<90 \mathrm{mmHg}$ ) in $68.2 \%$ of patients. The overall mean Mini-Mental State Examination (MMSE) score after 6 months of eprosartan-based therapy was one-point higher than at baseline $(P<0.001)$. MMSE score on completion of 6 months' follow-up was either unchanged or increased from baseline in $793(93 \%)$ individuals and decreased in 60 (7\%). Factors associated with stability of or improvement in cognitive function included MMSE score at baseline, diastolic blood pressure (DBP) at baseline, and treatment-induced change in DBP.

Conclusion: Results from the Middle East subgroup of OSCAR are supportive of the hypothesis that antihypertensive therapy based on angiotensin-receptor blocker therapy with eprosartan may be associated with preservation or improvement of cognitive function.

Keywords: hypertension, eprosartan, cognitive function, Middle East

\section{Introduction}

The Observational Study on Cognitive function And SBP Reduction (OSCAR) provided opportunities to investigate possible effects of eprosartan-based hypertension therapy on trends in cognitive performance in a very large community-dwelling population of patients with arterial hypertension managed in primary care.

The rationale and methodology of OSCAR have been described elsewhere ${ }^{1}$ and the principal findings from the overall study population have been reported. ${ }^{2}$ An original feature of this international cohort study is the recruitment of patients from countries not usually widely represented in such clinical research programs. This lack of participation contributes to the shortage of epidemiological data from these regions of the world. 
We now report the findings of a subgroup analysis of data from participants recruited in countries of the Middle East.

\section{Materials and methods}

OSCAR was conducted in 28 countries. ${ }^{1,2}$ The present subgroup analysis deals with data from patients recruited in Bahrain, Jordan, Kuwait, Lebanon, Qatar, Saudi Arabia, and the United Arab Emirates.

Male or female patients aged $\geq 50$ years with newly diagnosed hypertension (systolic blood pressure $[\mathrm{SBP}] \geq$ $140 \mathrm{mmHg}$ ) could participate in OSCAR if they were eligible for treatment with eprosartan $600 \mathrm{mg}$ /day once daily. Additional antihypertensive medication could be introduced after 1 month if the investigator considered the change in SBP to be insufficient. Hydrochlorothiazide $12.5 \mathrm{mg}$ /day given in a fixed-dose combination with eprosartan was preferred as the first add-in medication but investigators were allowed to choose whatever $\operatorname{drug}(\mathrm{s})$ they considered appropriate.

Blood pressure and safety data were collected at baseline, 1-3 months, and at 6 months. The Mini-Mental State Examination (MMSE) ${ }^{3}$ was used to assess cognitive function at baseline and at the end of the study. Validated locallanguage editions of the MMSE were issued to investigators, along with instructions for and information about correct implementation of the test.

\section{Statistical considerations}

Analyses were based primarily on the modified intentionto-treat (ITT) population, defined as all patients who received at least one dose of study treatment and who provided eligible relevant values at baseline and from at least one post baseline visit. The changes in MMSE score and arterial blood pressure between the baseline and post baseline visits were examined by a one sample $t$-test.

Nominal qualitative variables were analyzed using the Chi-square test. Ordinal qualitative variables were compared using the Wilcoxon test or the Mantel-Haenzel test, and quantitative variables were analyzed using analysis of variance (ANOVA). MMSE scores and blood pressure variables were compared between visits using covariance analysis, with baseline value as the covariate. Results are presented as means with standard deviations, with the exception of results derived from ANOVA, where the standard error of the mean was calculated.

A logistic regression analysis was used to assess the determinants of cognitive decline.

All statistical tests were performed using SAS software (v 9.1.3; SAS Institute, Cary, NC).

\section{Results}

\section{Patients and baseline characteristics}

A total of 42,412 patients was enrolled in OSCAR. Of these, 1317 were recruited from the seven countries of the Middle East participating in the study. A total of 853 patients was included in the Middle East ITT cohort (MEC), representing $64.8 \%$ of the total Middle East OSCAR population and 3.3\% of the total ITT cohort $(\mathrm{N}=25745)$. The derivation of that cohort is illustrated in Figure 1. The mean duration of therapy in the MEC was $178.5 \pm 52.1$ days.

Baseline characteristics of the MEC are summarized in Table 1. Compared with the residuum of the ITT population (RITT), the MEC was younger by an average of 4 years and had higher mean body mass index and mean arterial blood pressure $(\Delta 4 \mathrm{mmHg}$ for both SBP and diastolic

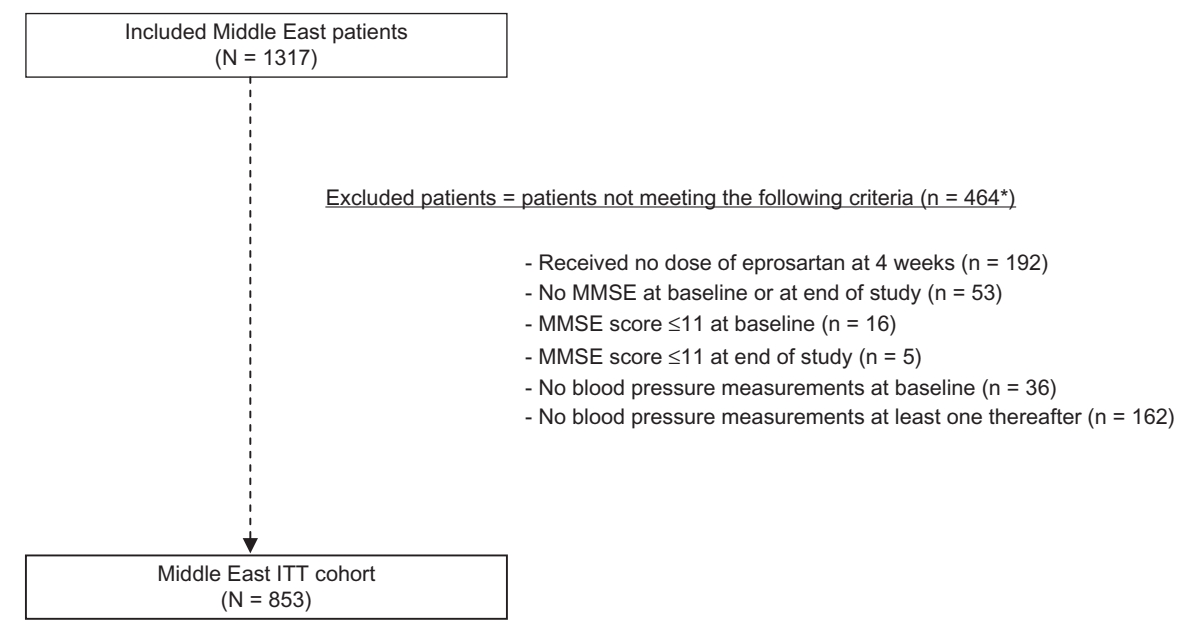

Figure I CONSORT summary for the MEC ITT cohort.

*Patients can meet multiple exclusion criteria.

Abbreviations: ITT, intention-to-treat; MMSE, Mini-Mental State Examination; MEC, Middle East ITT cohort. 
blood pressure [DBP]). Diabetes (39\% vs 23\%) and left ventricular hypertrophy ( $25 \%$ vs $19 \%$ ) were proportionately more prevalent in the MEC, where as hypercholesterolemia (56\% vs 63\%), coronary artery disease (11\% vs $15 \%)$, and arteriosclerosis (17\% vs $21 \%)$ were all less frequently recorded in $\operatorname{MEC}(P<0.001$ for all comparisons).

Initial MMSE score was significantly lower in the MEC than in the RITT $(P<0.001$; Table 1$)$; baseline MMSE score $<25$ was recorded in a higher proportion of MEC patients $(n=243$ [28.5\% vs 19\%]) indicating moderate cognitive impairment. (No statistical test of this difference was performed.) A further 257 patients (30.1\%) in the MEC had MMSE score 25-28, indicating mild cognitive impairment

Table I Baseline characteristics of the Middle East ITT population $(n=853)$

\begin{tabular}{|c|c|c|}
\hline & $\begin{array}{l}\text { MEC } \\
(n=853)\end{array}$ & $\begin{array}{l}\text { RITT } \\
(n=24892)\end{array}$ \\
\hline Bahrain & $28(2.1)$ & - \\
\hline Jordan & $92(7.0)$ & - \\
\hline Kuwait & $210(15.9)$ & - \\
\hline Lebanon & $169(12.8)$ & - \\
\hline Qatar & $108(8.2)$ & - \\
\hline Saudi Arabia & $496(37.7)$ & - \\
\hline United Arab Emirates & $214(16.3)$ & - \\
\hline Age (years); mean $\pm S D^{a}$ & $57.9 \pm 7.0$ & $64.4 \pm 9.5$ \\
\hline No. of males/females ${ }^{a}$ & $\begin{array}{l}529 / 323 \\
(62 / 38)\end{array}$ & $\begin{array}{l}|248| / \mid 2338 \\
(50 / 50)\end{array}$ \\
\hline $\mathrm{BMI}\left(\mathrm{kg} / \mathrm{m}^{2}\right) ;$ mean $\pm \mathrm{SD}^{\mathrm{a}}$ & $29.5 \pm 4.2$ & $27.6 \pm 4.1$ \\
\hline $\mathrm{SBP}(\mathrm{mmHg}) ;$ mean $\pm \mathrm{SD}^{\mathrm{a}}$ & $165.6 \pm 14.5$ & $161.8 \pm 12.9$ \\
\hline $\mathrm{DBP}(\mathrm{mmHg}) ;$ mean $\pm \mathrm{SD}^{\mathrm{a}}$ & $96.6 \pm 9.0$ & $92.9 \pm 8.8$ \\
\hline Pulse pressure $(\mathrm{mmHg})$; mean $\pm \mathrm{SD}^{\mathrm{b}}$ & $69.0 \pm 14.1$ & $68.8 \pm 12.8$ \\
\hline \multicolumn{3}{|l|}{ Type of hypertension ${ }^{\mathrm{a}}$} \\
\hline Isolated systolic hypertension & $132(15.5)$ & $6528(26.6)$ \\
\hline Systo-diastolic hypertension & $717(84.4)$ & $17999(73.1)$ \\
\hline \multicolumn{3}{|l|}{ Tobacco use } \\
\hline Smokers & $224(27.6)$ & $4,839(20.7)$ \\
\hline Ex-smokers & $143(17.6)$ & 6,334 (27.1) \\
\hline \multirow[t]{2}{*}{ Nonsmokers } & $444(54.8)$ & 12,170 \\
\hline & & $(52.2)$ \\
\hline Hypercholesterolemia $^{a}$ & 467 & $|5,46|$ \\
\hline Diabetes $^{\mathrm{a}}$ & 325 & 5,679 \\
\hline Family history of cardiovascular disease ${ }^{a}$ & 300 & 11,507 \\
\hline Coronary artery disease $\mathrm{e}^{\mathrm{a}}$ & 95 & 3,587 \\
\hline Left ventricular hypertrophy ${ }^{\mathrm{a}}$ & 203 & 4,556 \\
\hline Angina pectoris ${ }^{\mathrm{a}}$ & 71 & 3,064 \\
\hline MMSE score; ${ }^{*}$ mean \pm SD $^{a}$ & $26.1 \pm 4.3^{*}$ & $27.1 \pm 3.3$ \\
\hline MMSE $<25$ & $243(28.5)$ & $4645(18.7)$ \\
\hline MMSE 25-28 & $257(30.1)$ & $9105(36.6)$ \\
\hline MMSE $>28$ & $353(4 I .4)$ & $11142(44.8)$ \\
\hline
\end{tabular}

Notes: Unless stated otherwise, values shown represent numbers of patients, with percentages in parentheses. Data from the residuum of the intention-to-treat (ITT) population (RITT) are included for comparison. *Maximum possible score $=30$; mean scores for men and women were $26.9 \pm 3.9$ and $24.9 \pm 4.6$, respectively $(P<0.001$ by ANOVA $)$. a $P<0.001 ; b P=0.723 ; c P=0.513$.

Abbreviations: BMI, body mass index; SBP, systolic blood pressure; DBP, diastolic blood pressure; MMSE, Mini-Mental State Examination. (vs 36.4\% of RITT). Average baseline MMSE score was higher in men than in women in the MEC $(26.9 \pm 3.9$ vs $24.9 \pm 4.6 ; P<0.001)$. Trends were identified for a higher MMSE score with higher level of formal education and a lower MMSE score with advancing age $(P<0.001$ for both).

At baseline, 607 patients were recorded as being prescribed no or one antihypertensive drug, 150 were being prescribed two drugs, and the remaining patients were receiving three or more antihypertensive drugs. After entry into the study, 459 patients $(53.8 \%)$ were assigned to eprosartan monotherapy, 237 (27.8\%) to treatment with two drugs, and $157(18.4 \%)$ to three or more drugs. Supplementary medications were mostly beta blockers, calcium channel blockers or nonhydrochlorothiazide diuretics. At baseline, MEC patients on monotherapy had a higher mean MMSE (26.4) than those who were on multiple combination therapy (25.3) $(P=0.017)$. At the conclusion of the study, 459 patients in the MEC were using eprosartan only, 237 were taking eprosartan plus one other drug and 157 were using at least three drugs. This distribution was similar to that in the RITT.

\section{Blood pressure response}

Arterial blood pressure (SBP/DBP) decreased to $132.7 \pm 10.5 / 82 \pm 6.3 \mathrm{mmHg}$ over the course of the study ( $P<0.001 \mathrm{vs}$ baseline for both SBP and DBP). Mean blood pressure reduction was $32.9 \pm 14.3 / 14.6 \pm 8.6 \mathrm{mmHg}$ $(P<0.001)$. These responses were significantly larger than those in the RITT $(-25.6 \pm 14.0 \mathrm{mmHg}$ systolic, $-12.2 \pm$ $9.1 \mathrm{mmHg}$ diastolic; $P<0.001$ for MC vs RITT). Most $(\approx 79 \%)$ of the net blood pressure reductions were recorded between baseline and the first in-study visit (ie, during the first 12 weeks of the study).

Mean pulse pressure was reduced by $18.3 \pm 13.1 \mathrm{mmHg}$, a significant reduction from baseline and larger than that in the RITT $(13.6 \pm 12.9 \mathrm{mmHg} ; P<0.001$ for both comparisons). Normalization of blood pressure, defined as $\mathrm{SBP}<140 \mathrm{mmHg}$ and $\mathrm{DBP}<90 \mathrm{mmHg}$, was recorded in 582 MEC patients (68.2\%); this result compared favorably with the normalization rate in the RITT $(59.5 \% ; P=0.001)$. A response to therapy, defined as $\mathrm{SBP}<140 \mathrm{mmHg}$ and/or reduction in $\mathrm{SBP} \geq 15 \mathrm{mmHg}$ or $\mathrm{DBP}<90 \mathrm{mmHg}$ and/or reduction in DBP $\geq 10 \mathrm{mmHg}$ was recorded in 763 patients (89.4\%; vs RITT 91.6\%; $P=0.026)$.

\section{Evolution of MMSE score}

The overall mean MMSE score in the MEC after 6 months of eprosartan-based therapy was $27.2 \pm 3.6$, a 1 -point increase 
from the baseline value $(P<0.001)$. In the RITT cohort $(\mathrm{n}=24,892)$ the corresponding MMSE values were $27.1 \pm 3.3$ and $27.9 \pm 2.8$ : this 0.8 increase from the baseline value was also significant $(P<0.001)$. MMSE score post baseline was either unchanged $(n=392)$ or increased $(n=401)$ from baseline $(\mathrm{N}=793 ; 93.0 \%)$ and decreased in 60 individuals $(7.0 \%)$.

No statistically significant influences on the evolution of MMSE score were demonstrated for sex, age, level of formal education, or residence (urban vs rural). Test performance within each category of baseline MMSE score (<25, 25-28, 29-30) did not vary substantially between baseline and the end of the study. The factors most strongly associated with stability of or improvement in cognitive function were MMSE score at baseline, DBP at baseline and in-study change in DBP (Table 2).

\section{Safety and tolerability}

A total of seven treatment-emergent adverse drug reactions (ADRs) was recorded in the Middle East safety population ( $n=1317)$, of which four were considered to be possibly $(n=2)$, probably $(n=1)$, or highly probably $(n=1)$ related to study medication. One ADR led to treatment termination and two to study discontinuation. None of the recorded ADRs was classified as severe or serious. Nervous system disorders (three events in three patients) were the most frequently recorded form of ADR. No deaths occurred in the MEC.

\section{Discussion}

This analysis of the MEC is the largest source of prospectively gathered data about cognitive status in patients in the Middle East undergoing eprosartan-based antihypertensive therapy. In this population, as in the larger OSCAR ITT cohort, eprosartan-based therapy for a period of 6 months was associated with significant improvement in MMSE score. These data are prima facie consistent with earlier reports of improved cognitive function associated with a reduction in arterial blood pressure. ${ }^{4}$ Our study is the first of its type to report the influence of blood pressure on cognitive function for the countries of the Middle East.

Correlations between the evolution of MMSE score and arterial blood pressure responses in the MEC were more

Table 2 Factors associated with stability of or increase in MMSE score

\begin{tabular}{ll}
\hline Factor & OR (95\% Cl) \\
\hline Baseline MMSE score & $0.93(0.87-1.0)$ \\
Baseline DBP & $0.95(0.91-1.0)$ \\
$\Delta$ DBP & $0.96(0.91-1.0)$ \\
\hline
\end{tabular}

Abbreviations: $\mathrm{Cl}$, confidence interval; DBP, diastolic blood pressure; MMSE, Mini-Mental State Examination; OR, odds ratio. marked for DBP than SBP (though even for DBP the association was not strong (Table 2)). This primacy of DBP is somewhat at variance with the overall results of OSCAR but in keeping with the work of Elias et al, ${ }^{5}$ who have proposed that diminished cognitive performance is an essential intermediary between high blood pressure and physical disability, and who have identified, via path analysis, numerous aspects of cognitive function linking higher blood pressure with loss of physical ability. It should be noted also that the reduction in pulse pressure with eprosartan in the MEC was large $(\Delta 18.3 \mathrm{mmHg}$; $P<0.001$ vs RITT). Effects of eprosartan on aortic pulse wave velocity have been documented and related to impairment of cognition. ${ }^{6-9}$ Pulse pressure may act as a crude proxy for such effects, and may reflect a reduction in arterial stiffness in response to angiotensin-receptor blocker (ARB) therapy. ${ }^{10}$

Dementia is one of the principal neurological disorders leading to loss of autonomic function in the elderly. Although demographic trends and social practices in the Arab world mean that the impact of dementia is likely to be less marked in the short and medium term than in other regions of the world, measures to limit the risk of developing dementia are self-evidently desirable as a contribution to the health of older persons. ${ }^{11}$ Observational data in older Arab men suggest a correlation between higher blood pressure and cognitive impairment, ${ }^{12}$ whereas other reports have documented an extensive prevalence of classic cardiovascular risk factors and a rising prevalence of metabolic syndrome in Arab populations. ${ }^{13-18}$ The possibility of preserving cognitive function coincidentally in conjunction with efforts to reduce hypertension-related cardiovascular risk is therefore an attractive idea and has contributed to interest in the possibility that antihypertensive therapy, particularly ARB therapy targeted at the brain renin-angiotensin system (B-RAS), may have beneficial effects on cognition (see Fournier et $\mathrm{al}^{9}$ for recent discussions of some possible mechanisms of benefit beyond blood pressure reduction, and Takeda et $\mathrm{al}^{19}$ for some recent perspectives on the concept of the B-RAS). Our findings are compatible with that possibility. It should be noted, however, that although statistically significant to quite a high degree $(P<0.001)$, our blood pressure and MMSE data come from a relatively small subgroup and their clinical relevance has to be considered in that context. In addition it has to be acknowledged that the study did not include a control group.

Experience in the MEC confirms the effectiveness and tolerability of eprosartan as a blood pressure-lowering agent, whether used alone or in combination. The clinical benefits likely to flow from reductions in arterial blood pressure have been amply demonstrated. Evidence from several ARB studies of reductions in stroke risk and new-onset 
diabetes may be especially relevant, given that the MEC was a population characterized by high prevalences of left ventricular hypertrophy and the elements of metabolic syndrome, and given concerns about improving stroke awareness and hypertension control in the Middle East. ${ }^{20}$

The tolerability of eprosartan in the MEC subset of OSCAR was very good, as in the study overall. The recorded ADR incidence of $\approx 1.5 \%$ (of which none were classified as either serious or severe) is compatible with the overall findings of OSCAR, experience in randomized trials of eprosartan, and the characterization of 'placebo-like' tolerability ${ }^{21}$ for this drug. No deaths occurred in the MEC and those that were recorded elsewhere during the study were not associated with the use of eprosartan.

In conclusion, use of eprosartan as sole or primary hypertension medication was associated with an increase in the mean MMSE score in this subpopulation of the OSCAR study. These observations support the proposition that use of eprosartan to treat hypertension may delay or prevent cognitive decline in people with high blood pressure.

\section{Acknowledgment}

Hughes associates of Oxford, UK, provided writing and editorial assistance in the preparation of this manuscript.

\section{Disclosure}

The authors declare no conflicts of interest in this work.

\section{References}

1. Pathak A, Hanon O, Negré-Pages L, Sevenier F; on behalf of the OSCAR investigators. Rationale, design and methods of the OSCAR study: observational study on cognitive function and systolic blood pressure reduction in hypertensive patients. Fundam Clin Pharmacol. 2007;21: 199-205.

2. Hanon O, Berrou JP, Negré-Pages L, et al; on behalf of the OSCAR investigators. Effects of hypertension therapy based on eprosartan on systolic arterial blood pressure and cognitive function: primary results of the Observational Study on Cognitive function and Systolic Blood Pressure Reduction open-label study. J Hypertens. 2008;26: $1642-1650$

3. Folstein MF, Folstein SE, McHugh PR. "Mini-mental state". A practical method for grading the cognitive state of patients for the clinician. J Psychiatr Res. 1975;12:189-198.

4. Birns J, Morris R, Donaldson N, Kalra L. The effects of blood pressure reduction on cognitive function: a review of effects based on pooled data from clinical trials. J Hypertens. 2006;24:1907-1914.

Vascular Health and Risk Management

\section{Publish your work in this journal}

Vascular Health and Risk Management is an international, peerreviewed journal of therapeutics and risk management, focusing on concise rapid reporting of clinical studies on the processes involved in the maintenance of vascular health; the monitoring, prevention and treatment of vascular disease and its sequelae; and the involvement of
5. Elias MF, Dore GA, Davey A, Robbins MA, Elias PK. From blood pressure to physical disability. The role of cognition. Hypertension. 2010;55:1360-1365.

6. Scuteri A, Tesauro M, Appolloni S, Preziosi F, Brancati AM, Volpe M. Arterial stiffness as an independent predictor of longitudinal changes in cognitive function in the older individual. $J$ Hypertens. 2007;25: $1035-1040$.

7. Hanon $\mathrm{O}$, Haulon S, Lenoir H, et al. Relationship between arterial stiffness and cognitive function in elderly subjects with complaints of memory loss. Stroke. 2005;36:2193-2197.

8. Dhakam Z, McEniery CM, Yasmin, Cockcroft JR, Brown MJ, Wilkinson IB. Atenolol and eprosartan: differential effects on central blood pressure and aortic pulse wave velocity. Am J Hypertens. 2006;19: 214-219.

9. Fournier A, Oprisiu-Fournier R, Serot JM, et al. Prevention of dementia by antihypertensive drugs: how AT1-receptor-blockers and dihydropyridines better prevent dementia in hypertensive patients than thiazides and ACE-inhibitors. Expert Rev Neurother. 2009;9:1413-1431.

10. Schiffrin EL, Park JB, Intengan HD, Touyz RM. Correction of arterial structure and endothelial dysfunction in human essential hypertension by the angiotensin receptor antagonist losartan. Circulation. 2000; 101:1653-1659.

11. Yaffe K, Lindquist K, Vittinghoff E, et al; for the Health, Aging and Body Composition Study. The effect of maintaining cognition on risk of disability and death. J Am Geriatr Soc. 2010;58:889-894.

12. Israeli-Korn SD, Masarwa M, Schechtman E, et al. Hypertension increases the probability of Alzheimer's disease and of mild cognitive impairment in an Arab community in northern Israel. Neuroepidemiology. 2010;34:99-105.

13. Motlagh B, O’Donnell M, Yusuf S. Prevalence of cardiovascular risk factors in the Middle East: a systematic review. Eur J Cardiovasc Prev Rehabil. 2009;16:268-280.

14. Hammoudeh AJ, Al-Tarawneh H, Elharassis A, et al. Prevalence of conventional risk factors in Jordanians with coronary heart disease: the Jordan Hyperlipidemia and Related Targets Study (JoHARTS). Int J Cardiol. 2006;110:179-183.

15. Elabbassi WN, Haddad HA. The epidemic of the metabolic syndrome. Saudi Med J. 2005;26:373-375.

16. Baynouna LM, Revel AD, Nagelkerke NJ, Jaber TM, Omar AO, Ahmed NM. High prevalence of the cardiovascular risk factors in Al-Ain, United Arab Emirates. An emerging health care priority. Saudi Med J. 2008;29:1173-1178.

17. El-Shahat YI, Bakir SZ, Farjou N, et al. Hypertension in UAE citizens preliminary results of a prospective study. Saudi J Kidney Dis Transpl. 1999;10:376-381.

18. Jaddou HY, Bateiha AM, Ajlouni KM. Prevalence, awareness and management of hypertension in a recently urbanised community, eastern Jordan. J Hum Hypertens. 2000;14:497-501.

19. Takeda S, Sato N, Ogihara T, Morishita R. The renin-angiotensin system, hypertension and cognitive dysfunction in Alzheimer's disease: new therapeutic potential. Front Biosci. 2008;13:2253-2265.

20. Kamran S, Bener AB, Deleu D, et al. The level of awareness of stroke risk factors and symptoms in the Gulf Cooperation Council countries: Gulf Cooperation Council stroke awareness study. Neuroepidemiology. 2007;29:235-242.

21. Gavras HP. Issues in hypertension: drug tolerability and special populations. Am J Hypertens. 2001;14:231S-236S.

\section{Dovepress}

metabolic disorders, particularly diabetes. This journal is indexed on PubMed Central and MedLine. The manuscript management system is completely online and includes a very quick and fair peer-review system, which is all easy to use. Visit http://www.dovepress.com/ testimonials.php to read real quotes from published authors. 